\title{
Calcium Urine Excretion Rate
}

National Cancer Institute

\section{Source}

National Cancer Institute. Calcium Urine Excretion Rate. NCI Thesaurus. Code C117831.

A determination of the amount of calcium being excreted in urine over a defined period of time. 